sàn chậu trên 60 tuổi". Điện Quang Việt Nam, 31 (7), 79 - 84.

4. Piloni V, Bergamasco M, Melara G, et al (2018). "The clinical value of magnetic resonance defecography in males with obstructed defecation syndrome". Tech Coloproctol, 22 (3), 179-190.

5. Halligan S, Malouf A, Bartram; C I (2001). "Predictive Value of Impaired Evacuation at
Proctography inDiagnosing Anismus". AJR, 177 $633-636$.

6. Chu W C, Tam Y H, Lam W W, et al (2007) "Dynamic MR assessment of the anorectal angle and puborectalis muscle in pediatric patients with anismus: technique and feasibility". J Magn Reson Imaging, 25 (5), 1067-1072.

\title{
THỰC TRANG NHIỄM TRÙNG CATHETER ĐƯỜNG VÀO MACH MÁU TRÊN BỆNH NHÂN LỌC MÁU CẤP CỨU VÀ MộT Số YẾU TỐ LIÊN QUAN
}

\section{TÓM TẮT}

Nhiễm trùng catheter đường vào mạch máu là biến chứng nguy hiểm và là nguyên nhân tăng tỷ lệ mắc bệnh đáng kể, phải loại bó ống thông và tăng tỷ lệ tử vong với bệnh nhân được đặt catheter. Mục tiêu của nghiên cứu là khảo sát tình trạng nhiễm trùng và một số yếu tố ảnh hưởng đến tỷ lệ nhiễm trùng ở bệnh nhân lọc máu cấp cứu. Đối tượng và phương pháp: Mô tả 52 trường hợp nghi ngờ nhiễm trùng liên quan đến catheter tại bệnh viện Bạch Mai từ tháng 3 năm 2019 đến tháng 3 năm 2021. Kết quả và bàn luận: Tuổi trung bình 46,85 \pm 20,15 (16-85 tuổi), tỷ lệ nam: nữ là 2,25:1. Nhóm có sốt chiếm $82,7 \%$, nhóm không sốt chiếm $17,3 \%$. TM đùi phải là vị trí nhiễm khuẩn thường gặp nhất khi đặt catheter. Trên lâm sàng hay găp biêu hiên chảy dịch tai vị trí đă̆t. Vi khuẩn gây bệnh chủ yếu là S.aureus, tỷ lệ nhiếm khuẩn huyết do S. aureus của mẫu nghiên cứu là $28 / 38(75,7 \%)$. Các yếu tố như giới tính nam, mùa đặt làm tăng tỷ lệ nhiễm khuẩn. Các yếu tố như tiền sử bênh, mức đổ thiếu máu, tình trạng dinh dưỡng không làm tăng tỷ lể nhiễm khuẩn huyết của bệnh nhân. Kết luận: Tỷ lệ̉ nhiễm khuẩn huyết liên quan đễn catheter chiếm $75,7 \%$, chủ yếu là $\mathrm{S}$. aureus. Nhiếm trùng liên quan đến catheter trên bệnh nhân lọc máu cấp cứu có thể ở bất cứ lứa tuổi nào, thường gặp ở nam. Các yếu tố như thời gian đặt, mùa đặt làm tăng tỷ lệ nhiếm khuẩn. Cần chú ý hướng dẫn bệnh nhân vệ sinh và chăm sóc catheter khi có catheter lọc máu. máu.

Tư khóa: Nhiễm trùng liên quan đến catheter, lọc

\section{SUMMARY}

CATHETER ASSOCIATEDVASCULAR ACCESS INFECTIONSSTATUS IN ACUTE HEMODIALYSIS

\section{PATIENTS AND SOME RELATED FACTORS}

Catheter vascular access infections are serious

\author{
${ }^{1}$ Trường Đại học Y Hà Nội \\ ${ }^{2}$ Tt Thận - tiết niệu và lọc máu, Bệnh viện Bạch Mai \\ Chịu trách nhiệm chính: Vũ Thị Trung Anh \\ Email: Singum95@gmail.com \\ Ngày nhận bài: 25.6.2021 \\ Ngày phản biên khoa hoc: 17.8.2021 \\ Ngày duyệt bài: 26.8.2021
}

\section{Vũ Thị Trung Anh ${ }^{1}$, Mai Thị Hiền ${ }^{2}$}

complication anda significant cause of morbidity and mortality for HD patients. The aims of thestudy were to evaluate catheter - related infections and to indentify some factors related increase the catheter related infectionsin acute hemodialysis patients. Subjects and methods: Described 52 cases at high risk of catheter - related infections in Bach Mai hospital from March 2019 to March 2021. Results: The meanage: $46,85 \pm 20,15$ years (16-85years), The ratio of males to females is 2,25:1. Group with fever sign is $82,7 \%$,group with non-fever sign $17,3 \%$. The most common site of infection is the right femoral venous catheter.The most common manifestation is drainage from the exit site. The most frequent pathogens identified were $\mathrm{S}$. aureus. The rate of catheter - related bloodstream infections are28/38 $(75,7 \%)$. For male sex and season to outureteral stent were significant risk factors for thedevelopment of catheter - related infections. Conclusions: The rate of Catheter-related bloodstream infections accounted for $75.7 \%$, mostly is S. aureus. Catheter-related infections in HD patients can occur at any age, and are more common in males. The rate of Catheterrelated infections accounted for $75.7 \%$, mostly is S. aureus. For male sex and season to outureteral stent were significant risk factors for thedevelopment of catheter - related infections. Patients should be instructed catheter cleaning and monitoring in the dialysis care process.

Keywords: catheter related infections, hemodialysis.

\section{I. ĐĂT VẤN ĐỀ}

Đă̆t catheter vào các tĩnh mạch trung tâm (TMTT)để lọc máu vừa là đường vào tạm thời, vừa là đường vào lâu dài với 1 số trường hợp không làm được nối thông động tĩnh mạch. Nhiễm trùng là biến chứng nguy hiểm và đe dọa đến tính mạng của việc đặt catheter vào mạch máu và là nguyên nhân tăng tỷ lệ mắc bệnh đáng kể, phải loại bỏ ông thông và tăng tỳ lệ tử vong [1] , ở Hoa Kỳ có thể quy cho tỳ lệ tử vong từ $12 \%$ đến $25 \%$ [2]. Tình trạng, đặc điểm nhiễm trùng catheter cũng thay đổi theo địa lý và thời gian. Chính vì vậy chúng tôi tiến hành nghiên cứu: "Thực trạng nhiếm trùng catheter 
đường vào mạch máu ở bệnh nhân lọc máu cấp cứu và một số yếu tố liên quan"

\section{II. ĐỐI TƯƠ'NG VÀ PHƯƠNG PHÁP NGHIÊN CỨU}

Đối tượng: Là các bệnh nhân >=16 tuổi có chỉ định đặt catheter TMTT để lọc máu cấp cứu, được theo dõi và điều trị tại khoa Thận- Tiết niệu - bệnh viện Bạch Mai từ tháng 3 năm 2019 đển tháng 3 năm 2021 và theo tiêu chuẩn của KDOQI2019:

- Nhiếm trùng chân ống Catheter: sưng nề, chai cứng và hoặc đau từ $\leq 2 \mathrm{~cm}$ từ vị trí chân ống catheter. Có thể có chảy dịch mủ từ chân ống.

- Nhiễm trùng huyết liên quan catheter: bệnh nhân có catheter TMTT chạy thận nhân tạo có biểu hiện nhiễm trùng trên lâm sàng và có ít nhất 1 mẫu cấy máu dương tính ở ngoại vi (từ mạch chạy thận nhân tạo hoặc từ máu tĩnh mạch ngoại biên) và không có ổ nhiễm trùng nào khác.

Phương pháp nghiên cứu: Mô tả cắt ngang, hồi cứu và tiến cứu

Loại trừ tất cả các bệnh nhân nghi ngờ có nhiếm trùng không liên quan đến catheter như: Có vết thương hở, viêm phổi, nhiễm khuẩn tiết niệu, nhiễm trùng ngoài da không phải tại chỗ đặt catheter.

Thiết kế và nhập số liệu, phân tích số liệu bằng phần mềm SPSS 20.0

\section{KẾT QUẢ NGHIÊN CỨU VÀ BÀN LUÂN}

Khảo sát trên 52 lần đặt Catheter được tiến hành trên 51 bệnh nhân từ tháng 3 năm 2019 đến tháng 3 năm 2021, được chia thành 2 nhóm:

+ Nhóm 1: Số lần đặt Catheter có sốt, 43 lần đặt $(82,7 \%)$

+ Nhóm 2: Số lần đặt Catheter không sốt, 9 lần đặt (17,3\%); Chúng tôi ghi nhận:

- Tuổi trung bình trong nhóm nghiên cứu là $46,85 \pm 20,15$ (nhỏ nhất là 16, lớn nhất là 85 )

- Nam có 36/52 trường hợp (69,2\%), nữ có 16/52 trường hợp (30,8\%). Tỷ lệ nam nhiều hơn nữ, sự khác biêt có ý nghĩa thống kê.

- Vị trí nhiễm trùng liên quan đến catheter thường gặp nhất là tĩnh mạch đùi phải $46 / 52$ trường hợp $(88,5 \%)$, trong đó trường hợp có sốt là $82,6 \%$ và không sốt là $17,4 \%$

- Đặt Catheter vào mùa xuân chiếm tỷ lệ cao nhất trong mẫu nghiên cứu $(46,2 \%)$ và cả 2 nhóm.

Bảng 1: Số lần chạy thận trung bình/1 catheter

\begin{tabular}{|l|c|c|c|c|c|}
\hline \multirow{2}{*}{} & \multicolumn{3}{|c|}{ Số lần chạy thận nhân tạo (lần) } \\
\cline { 2 - 6 } & $\mathbf{X} \pm$ SD & $\mathbf{n}$ & $\mathbf{p}$ & Minn & Max \\
\hline Nhóm 1 & $3,65 \pm 1,77$ & 43 & 0,22 & 1 & 8 \\
\hline
\end{tabular}

\begin{tabular}{|l|c|c|l|l|l|}
\hline Nhóm 2 & $5,44 \pm 3,2$ & 9 & & 2 & 12 \\
\hline Chung & $3,96 \pm 2,16$ & 52 & & 1 & 12 \\
\hline
\end{tabular}

Nhận xét: Số lần chạy thận của nhóm không sốt cao hơn nhóm sốt, sự khác biệt này không có ý nghĩa thống kê ( $p>0,05)$.

Bảng 2. Số ngày sử dụng trung binh/1 catheter

\begin{tabular}{|c|c|c|c|c|c|}
\hline & \multicolumn{5}{|c|}{ Số ngày sử dụng Cathter } \\
\cline { 2 - 6 } & $\mathbf{x} \pm$ SD & $\mathbf{n}$ & $\mathbf{p}$ & Min & Max \\
\hline Nhóm 1 & $8,44 \pm 4,42$ & 43 & & 2 & 21 \\
\hline Nhóm 2 & $13,78 \pm 8,76$ & 9 & 0,009 & 3 & 31 \\
\hline Chung & $9,37 \pm 5,68$ & 52 & & 2 & 31 \\
\hline
\end{tabular}

Nhân xét: Thời gian sử dụng Catheter trung bình/1 lần đặt của nhóm không sốt dài hơn so với nhóm sốt, sự khác biệt này có ý nghĩa thông kê $(p<0,05)$.

Bảng 3. Các dấu hiệu nhiễm trùng tại chố của 2 nhóm

\begin{tabular}{|c|c|c|c|c|}
\hline & $\begin{array}{c}\text { Chung } \\
\text { n(\%) }\end{array}$ & $\begin{array}{c}\text { Nhóm 1 } \\
\text { n(\%) }\end{array}$ & $\begin{array}{c}\text { Nhóm } \\
\mathbf{2} \text { n(\%) }\end{array}$ & p \\
\hline Đau & $19(36,5)$ & $18(41,9)$ & $1(11,1)$ & 0,13 \\
\hline Nề & $21(40,4)$ & $17(39,5)$ & $4(44,4)$ & 1,0 \\
\hline Đỏ & $19(36,5)$ & $15(34,9)$ & $4(44,4)$ & 0,708 \\
\hline
\end{tabular}

\begin{tabular}{l|l|l|l|l}
\hline Chảy dịch & $30(57,7)$ & $23(53,5)$ & $7(77,8)$ & 0,272 \\
\hline
\end{tabular}

Nhận xét: Trong các dấu hiệu lâm sàng thì biểu hiện chảy dịch tại chỗ chiếm tỷ lệ cao nhất $(57,7 \%)$. Không có sự khác biệt về dấu hiệu nhiếm trùng tại chỗ giữa 2 nhóm.

Bảng 4. Kêt qưa phân lập vỉ khuẩn từ đầu trong catheter và máu ngoại vi

\begin{tabular}{|c|c|c|c|c|}
\hline \multicolumn{2}{|c|}{ Số lượng } & \multicolumn{3}{|c|}{ Cấy đầu trong catheter } \\
\cline { 2 - 5 } & $(+)$ & $(-)$ & Tống \\
\hline \multirow{2}{*}{$\begin{array}{c}\text { Cây } \\
\text { máu }\end{array}$} & $(+)$ & 28 & 0 & 28 \\
\cline { 2 - 5 } & $(-)$ & 9 & 1 & 10 \\
\cline { 2 - 5 } & Tống & 37 & 1 & 38 \\
\hline
\end{tabular}

Nhân xét: - Trong tất cả các trường hợp được tiến hành đồng thời cấy đầu trong Catheter và máu ngoại vi, trong đó có 28 trường hợp cùng cho kết quả $(+)$ với $S$. aureus

- Tỷ lệ NKH do S. aureus của mẫu nghiên cứu là 28/38 trường hợp tương đương 75,7\%.

Bảng 5: Mối liên quan giữa bệnh lý nền của 2 nhóm nghiên cứu

\begin{tabular}{|c|c|c|c|c|}
\hline & $\begin{array}{c}\text { Chung } \\
\text { n(\%) }\end{array}$ & $\begin{array}{c}\text { Nhóm 1 } \\
\text { n(\%) }\end{array}$ & $\begin{array}{c}\text { Nhóm 2 } \\
\text { n(\%) }\end{array}$ & p \\
\hline DTÐ & $9(17,3)$ & $9(20,9)$ & $0(0,0)$ & 0,33 \\
\hline THA & $33(63,5)$ & $29(67,4)$ & $4(44,4)$ & 0,26 \\
\hline
\end{tabular}

Suy thận mạn $30(57,7) 24(55,8) 6(66,7) \quad 0,717$

\begin{tabular}{lll|lll|} 
Suy tim & $8(15,4)$ & $6(22,2)$ & $2(14,0)$ & 0,615
\end{tabular}

Nhận Xét: Trong các trường hợp được nghiên cứu thì tiền sử tăng huyết áp là hay gặp nhất $(63,5 \%)$. Không có sự khác biệt về bệnh lý nền giữa 2 nhóm nghiên cứu. 
VIETNAM MEDICAL JOURNAL N02 - SEPTEMBER - 2021

Bảng 6: Mối liên quan với mức đô thiếu máu của 2 nhóm

\begin{tabular}{|c|c|c|c|c|c|c|c|}
\hline \multirow{2}{*}{$\begin{array}{c}\text { Mức độ thiếu } \\
\text { mảu }\end{array}$} & \multicolumn{2}{|c|}{ Nhóm 1} & \multicolumn{2}{|c|}{ Nhóm 2} & \multirow[b]{2}{*}{$\mathbf{p}$} & \multicolumn{2}{|c|}{ Chung } \\
\hline & $n=43$ & $\%$ & $n=9$ & $\%$ & & $n=52$ & $\%$ \\
\hline Bình thường & 3 & 7,0 & 0 & 0 & \multirow{4}{*}{0,927} & 3 & 5,8 \\
\hline Nhẹ & 4 & 9,3 & 1 & 11,1 & & 5 & 9,6 \\
\hline Vứa & 22 & 51,2 & 4 & 44,4 & & 26 & 50,0 \\
\hline Nặng & 14 & 32,6 & 4 & 44,4 & & 18 & 34,6 \\
\hline
\end{tabular}

Nhận xét: Tỷ lệ thiếu máu ở chung của 2 nhóm chiếm 94,2 \%, trong đó thiếu máu mức độ vừa và nặng chiếm $84,6 \%$. Không có sự khác biệt về mức độ thiếu máu giữa 2 nhóm.

Bảng 7: Mối liên quan với chỉ số albumin huyết thanh của 2 nhóm

\begin{tabular}{|c|c|c|c|c|c|c|c|}
\hline & \multicolumn{2}{|l|}{$\bar{x}$ Nhóm 1} & \multicolumn{2}{|l|}{$\bar{x}$ Nhóm 2} & \multirow[t]{2}{*}{ p } & \multicolumn{2}{|l|}{ Chung } \\
\hline & & $n$ & & $n$ & & $\bar{x} \pm$ SD & $\mathbf{n}$ \\
\hline Albumin & $31,82 \pm 6,73$ & 43 & $32,79 \pm 7,04$ & 9 & 0,701 & $31,9942 \pm 6,73$ & 52 \\
\hline
\end{tabular}

Nhân xét: Chỉ số albumin huyết thanh trung bình của nhóm sốt $(31,82 \pm 6,73)$ thấp hơn so với nhóm không sốt $(32,79 \pm 7,04)$. Sự khác biệt không có ý nghĩa thống kê.

\section{BÀN LUÂ̂N}

Trong số 51 bệnh nhân nghiên cứu tuổi trung bình của nhóm là 46,85 $\pm 20,15$ (nhỏ nhất là 16, lớn nhất là 85 ). Như vậy tình trạng nhiễm trùng liên quan đến catheter có thể gặp ở bất kỳ lứa tuổi nào ở các bệnh nhân lọc máu cấp cứu. Tỷ lệ nam: nữ là $2,25: 1$, sự khác biệt có ý nghĩa thống kê, nhiếm trùng catheter gặp ở nam giới nhiều hơn. Điều này có sự khác biệt với nghiên cứu của Su Văn Na Mê Thy Phan Khăm, tỷ lệ nam và nữ ở bệnh nhân STM lọc máu chu kỳ là 1:1 [3], theo Lê Ngọc Hà [4] tỷ lệ nam/nữ trong nhóm bệnh nhân nghiên cứu 1,53:1. Có sự khác biệt này là do sự khác biệt về đối tượng nghiên cứu, nhóm bệnh nhân của các nghiên cứu này là bệnh nhân lọc máu chu kì, còn bệnh nhân trong nghiên cứu của chúng tôi bao gồm cả bệnh nhân suy thận cấp.

Vị trí đặt catheter ở tĩnh mạch đùi phải hay gặp nhất, trong đó trường hợp có sốt $82,6 \%$. Theo Weyde $W$ và cộng sự đường vào ở TM đùi là dễ đặt catheter nhất nhưng lại dễ nhiễm khuẩn nhất khi catheter phải để lâu quá 72 tiếng, nên với bệnh nhân cần sử dụng catheter lâu dài thì TM cảnh trong là vị trí đặt thích hợp nhất [5]. Kết quả này cũng phù hợp với 1 số báo cáo gần đây. Theo Lê Ngọc Hà nhiễm trùng catheter TM đùi (chiếm $87,72 \%$ ), trong khi đó số bệnh nhân bị sốt khi đặt tĩnh mạch cảnh trong là 7/50 (chiếm 12,28\%). Việc đặt Catheter ở TM đùi có khả năng nhiễm khuẩn cao hơn so với TM cảnh trong rất nhiều.

Về mùa đă̆t và thời gian sử dung catheter. Đặt catheter vào mùa xuân chiếm tỷ lệ cao nhất trong mẫu nghiên cứu $(46,2 \%)$ và cả 2 nhóm. Có lẽ vì mùa ẩm là mùa thuân lợi cho các vi khuẩn gây bệnh phát triển, nhất là Việt Nam lại là một nước nhiệt đới có khí hậu nóng ẩm thì càng thuận lợi hởn. Thời gian sử dụng catheter trung bình ở nhóm sốt là ngắn hơn so với nhóm không sốt. Đồng thời số lần lọc máu trung bình/ 1 catheter của nhóm sốt cũng ít hơn nhóm không sốt. Không có sự khác biệt giữa 2 nhóm nghiên cứu. Chúng tôi thấy rằngkhi bệnh nhân có sốt nghi ngờ nhiễm trùng liên quan đến catheter, bệnh nhân được rút catheter sớm hơn, thời gian lưu catheter nhỏ nhất là 2 ngày (bảng 2).

Về đă̆c điểm lâm sàng và cận lâm sang. Trong 52 lần đặt catheter có 43 trường hợp bị sốt $(82,7 \%)$, có 9 trường hợp không ( $17,3 \%)$. Chảy dịch là dấu hiệu thường gặp nhất khi bệnh nhân có biểu hiện nhiễm khuẩn tại chỗ $(57,7 \%)$. Không có sự khác biệt giữa 2 nhóm sốt và không sốt. Đây là dấu hiệu gợi ý cho chúng ta rất nhiều trong chẩn đoán, nhắc nhở cần lưu ý theo dõi và chăm sóc đặc biệt khi bệnh nhân có biểu hiện chảy dịch tại vị trí đặt catheter, bởi bệnh nhân có nguy cơ bị nhiễm trùng. Tuy nhiên, ngay cả khi chân Catheter khô sạch chúng ta cũng không thế loại trừ nhiễm trùng catheter. Chỉ có 38 trong số $52 \mathrm{BN}$ được cấy đầu catheter và cấy máu ngoại vi đồng thời (bảng 4), có thể là do chỉ có bệnh nhân có sốt mới được cấy máu. Trong nhóm bệnh nhân này có 28 trường hợp được chẩn đoán nhiễm khuẩn huyết liên quan đến catheter đều cho kết quả (+) với S. aureus chiếm 75,7\%, như vậy kết quả nghiên cứu cao hơn nhiều so với nghiên cứu của Bernard Caunaud (5,9\%)[6] và nghiên cứu của Issam Raad MD $(3,1 \%)$. Có thể là do bệnh nhân trong nghiên cứu của chúng tôi có sốt cao hơn nhiều so với bệnh nhân không có sốt và những bệnh nhân có sốt trên lâm sàng thường được quan tâm hơn về vấn đề nhiễm trùng catheterS. aureus là nguyên nhân đường vào ngoài da hay gặp nhất trong nghiên cứu của chúng tôi và nhiêu nghiên cứu khác.

Về các yếu tố liên quan, trong nghiên cứu chúng tôi thấy rằngnhóm sốt có tỷ lệ bệnh nhân 
ĐTÐ cao hơn so với nhóm không sốt (20,9\% so với $0 \%$ ) (bảng 5). Như vậy, bệnh nhân lọc máucó ĐTĐ có nguy cơ nhiếm khuẩn huyết cao hơn so với các bệnh nhân không có ĐTĐ. Điều này cũng được nhận thấy ở nhiều nghiên cứu khác, theo Helene bệnh nhân bị ĐTĐ nguy cơ bị nhiễm khuẩn cao gấp 3 đến 4 lần so với người bình thường[7]. Nghiên cứu của Lê Ngọc Hà tỷ lệ sốt ở bệnh nhân ĐTĐ là 19,6\% [4]. THA là bệnh lý nền hay gặp nhất (63,5\%), không có sự khác biệt giữa 2 nhóm. Mức độ thiếu máu hay gặp nhất là thiếu máu vừa chiếm $50 \%$ và năng chiếm $34,6 \%$. Không có sự khác biệt về mức độ thiếu máu giữa 2 nhóm, do thiếu máu gặp hầu hết ở các bệnh nhân suy thận mạn. Chì số albumin huyết thanh trung bình của nhóm sốt $(31,82 \pm$ $6,73)$ thấp hơn so với nhóm không sốt $(32,79 \pm$ $7,04)$. Sự khác biệt không có ý nghĩa thống kê. Nhiêu tác giả trong nước và ngoài nước cũng ghi nhận tình trạng suy dinh dưỡng với albumin huyết thanh giảm sẽ làm tăng nguy cơ nhiễm trùng [4].

\section{KẾT LUÂN}

Nhiễm trùng liên quan đến catheter trên bệnh nhân lọc máu cấp cứu có thể ở bất cứ lứa tuổi nào, thường gặp ở nam. Vị trí đặt hay gặp nhiễm trùng nhất là catheter tĩnh mạch đùi phải, biểu hiện tại chỗ hay gặp là chảy dịch, vi khuẩn gây bểnh thường gặp là $\mathrm{S}$. aureus. Cần chú ý hướng dẩn bệnh nhân vệ sinh và chăm sóc catheter khi có catheter lọc máu.

\section{TÀI LIỆU THAM KHẢO}

1. Lemaire $X$, Morena $M$, Leray-Moragués $H$, et al. Analysis of risk factors for catheter related bacteremia in 2000 permanent dual catheters for hemodialysis. Blood Purif. 2009;28(1):21-28. doi: $10.1159 / 000210034$

2. Maki DG, Kluger DM, Crnich CJ. The risk of bloodstream infection in adults with different intravascular devices: a systematic review of 200 published prospective studies. Mayo Clin Proc. 2006;81(9):1159-1171. doi:10.4065/81.9.1159

3. Su Văn Na Mê Thy Phan Khăm. Đánh giá hiêu quả của một số đường dẫn máu ra ngoài cơ thể để lọc máu. Luận văn tiến sỹ, Trường Đại Học Y Hà Nội. 2001:1-27, 66, 70

4. Lề Ngọc Hà, Đố Gia Tuyển, Khảo sát tình trạng nhiếm trùng liên quan đên đường vào mạch máu tạm thời trong lọc máu cấp cứu ở bệnh nhân suy thận giai đoạn cuối Luận văn thạc sỹ், Trường Đại Học Y Hà Nội. 2015

5. WeydeW, $\mathbf{W} .$, KlingerM,Morawsleaz, Prolouged use of the femoral catheter as a temporary access for hemodialysis. Przegleki 54, 1997

6. CanaudBernard, Haemodialysis catheter-related infection: time for actions. Nephrol Dial Transplantation, 1994.

7. Helen Caivet MD, T.T., Yoshikawa MD, Infections in diabetes. 2001: p. 407-418.

\section{ĐÁNH GIÁ KẾT QUẢ ĐIỀU TRỊ UNG THƯ PHỔI KHÔNG TẾ BÀO NHỎ DI CĂN NÃO BẰNG XẠ PHẪU GAMMA KNIFE VÀ HÓA TRI PHÁC Đồ PEMETREXED-CARBOPLATIN (PC)}

\section{TÓM TẮT}

Mục tiêu: Nghiên cứu này nhằm mô tả một số đặc điểm lâm sàng, cận lâm sàng ở bệnh nhân ung thư phổi không tế bào nhỏ di căn não được điều trị bằng xạ phẫu Gamma Knife kết hợp hóa trị phác đồ Pemetrexed-Carboplatin tại Bệnh viện $K$ và Trung tâm Y học hạt nhân và Ung bướu, Bệnh viện Bạch Mai và đánh giá kết quả điều trị của nhóm bệnh nhân trên. Đối tượng và phương pháp nghiên cứu: Nghiên cứu mô tả hồi cứu kết hợp tiến cứu trên 65 bệnh nhân được chẩn đoán xác định là ung thư phổi không tế

\footnotetext{
${ }^{1}$ Bệnh viện Phổi Hải Dương

2Trường Đai hoc Y Hà Nội

${ }^{3}$ Bệnh viện đa khoa Tâm Anh

Chịu trách nhiệm chính: Nguyễn Công Đại

Email: mandini1987@gmail.com

Ngày nhân bài: 21.6.2021

Ngày phản biên khoa hoc: 16.8 .2021

Ngày duyệt bài: 23.8.2021
}

\section{Nguyễn Công Đại ${ }^{1}$, Nguyễn Văn Hiếu ${ }^{2}$, Vũ Hũu Khiêm ${ }^{3}$}

bào nhỏ không vảy di căn não, được điều trị bằng xa phẫu Gamma Knife kết hợp hóa trị phác đồ Pemetrexed-Carboplatin tại Bệnh viện $K$ và Trung tâm Y học hạt nhân và Ung bướu, Bệnh viện Bạch Mai từ tháng 1/2018 đến tháng 7/2021. Kết quả: Tuổi trung bình là $58,3 \pm 9,2$ tuổi, nam giới chiếm tỷ lệ $86,2 \%$, đặc điểm lâm sàng: hội chứng tăng áp lực nội sọ $(72,3 \%)$, ho khan $(61,5 \%)$, không có triệu chứng thần kinh $(18,5 \%)$. Đặc điêm hình ảnh MRI sọ não: u ở bán cầu đại não $(66,2 \%), 3$ u $(44,6 \%)$, kích thước u não di căn trên $10 \mathrm{~mm}(89,2 \%)$. Tỷ lệ đáp ứng khách quan toàn bô là $35,4 \%$, đáp ứng k̇hách quan tai não là $70,7 \%$, đáp ứng khách ngoài não là 36,9\%.Tỷ lệ kiểm soát bênh tai não là $90,7 \%$. Trung vi thời gian sống thêm bệnh không tiến triển (PFS) là 10,3 tháng. Trung vị thời gian sống thêm không tiến triển tại não là 10,8 tháng. Tác dụng phụ hay gặp là thiếu máu $(49,2 \%)$, buồn nôn $(40 \%)$, nôn $(20 \%)$, tăng men gan $(12,3 \%)$. Kết luận: Xạ phâuu Gamma Knife kết hợp hóa trị phác đồ Pemetrexed-Carboplatin là phương pháp điêu trị hiệu quả tốt trong ung thư phổ không tế bào nhỏ di 